\title{
Analysis of the Influence of Internal Control Environment on Accounting Information Quality
}

\author{
Sheng Shujun \\ Tianhua College of Shanghai Normal University \\ Shanghai, 201815
}

\begin{abstract}
Accounting information distortion has exis ted for a long time, but why? People blamed the accounting work belonging to the enterprise management system at the beginning, and the accounting principles and systems for standardizing enterprise accounting behavior. However, the related regulators and workers failed to solve the problem despite their hard work, which makes us have to consider the true reason. This paper tried to explore the deep reasons of accounting information distortion from the aspect of internal control environment.
\end{abstract}

Keywords-accounting information distortion; internal control environment; management layer

Authenticity is vital for accounting information quality. And accounting information must truly reflect the financial status, operating results and cash flow of an enterprise, which is the basic requirement for accounting information. Its authenticity has attracted more and more attention since the case of "South China Sea Company" in 1720, accounting fraud of the first listed company. Even though the modern audit technology has been greatly developed, and all the countries established and promoted financial accounting principles to guarantee the authenticity of accounting information, the problem of distortion didn't been curbed essentially. Taking America as the example, the related severe distortion cases in the 20th century involved "Giant Retail Company" (in 1972), "Martil Company” (in 1975), Enron Company(in 2001), World Communication Company(in 2002) and Adair Communication Company(in 2002). While such conditions also exist in China, such as Hongguang Stock, Qiongminyuan,
ST Dawn, Houwang Stock, Liantian Stock, Yinguangsha, Lvdadi and Wanfushengke.

People have made efforts to promote accounting principles and systems from the beginning of accounting distortion, but the problem haven't been solved basically.

A number of scholars hold the belief that accounting control is the curb of internal control and guarantee of accounting information quality. There is no doubt that a company cannot run well without corresponding accounting control system. However, most of current national listed companies failed to do, and the deficiency of control environment leads to the valid accounting control system, which the author thought we should compensate to solve the problem of accounting information distortion. As said in the internal control concept of COSO, internal control environment is the foundation to establish other factors. It will only waste the efforts if great deficiency exists in the foundation, even though other factors are perfect.

\section{COMPONENTS OF INTERNAL CONTROL ENVIRONMENT}

Internal control environment includes various factors of establishing, strengthening or weakening the specific policies, procedures and efficiencies. It is key to form other internal control factors and influences the control awareness of all the staff in the organization. An effective internal control cannot be formed without an effective control environment, no matter how the quality of other factors. Especially the attitude of management layer is crucial to the attitude and behavior of the whole enterprise. Internal control environment includes:

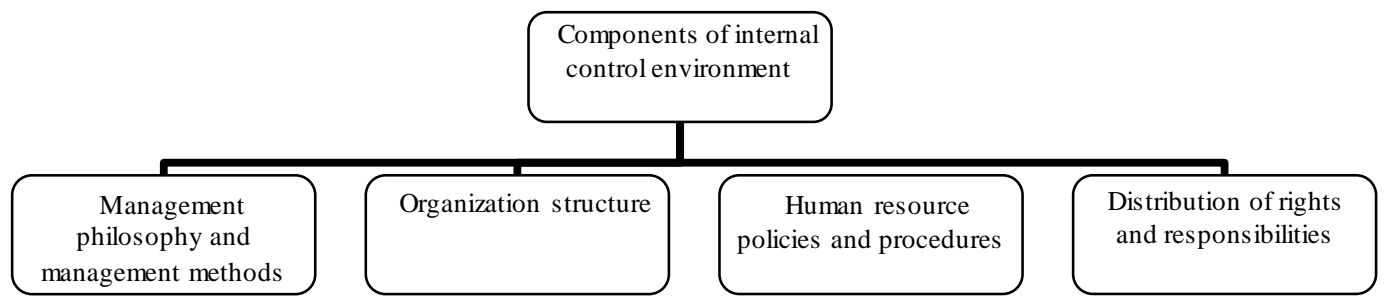

Fig. 1. Components of internal control environment

\section{A. Management philosophy and operation methods}

The key factor in the internal control environment is the attitude of management layer. They are closely related with the regulation and implementation of effective control policies. Their attitudes towards the control can have great influence on controlling the effectivity, helpful to give full play to the accounting system and curbing procedures. Their promotion of proper morality behavior will enhance the effect of control. If the staff of the company thinks the management layer is supposed to behavior with appropriate morality standard, then such behavior will expand to the whole group. Such morality behavior will reduce the false reporting of the financial 
statements to the least and improve the quality and accounting information, vice versa.

\section{B. Organization structure}

The distinct permission division in the organization structure is significant to improving the control. Organization structure and duty allocation system clarified the trusted responsibility of various activities, which is vital for the effective control and directly decides the control effect.

\section{Human resource policy and procedure}

Human resource function departments accomplish the control through allocation proper jobs for different people and making them have proper training for finishing assigned work. Clear and complete position explanation, effective training plans, definite employment policies and all-round communication are several important aspects for environment control. Only reasonable human policies and procedures can guarantee the normal operation of enterprises.

\section{Distribution of rights and responsibilities}

In order to realize the targets of enterprises and make the control policies and procedures implemented, the management layer must let the whole group know the method of authority and responsibility division. The specific contents include the establishment of policy brochures, organization structure, holding meeting, careful supervision and performance report system.

\section{INTERNAL CONTROL ENVIRONMENT AND ACCOUNTING INFORMATION QUALITY}

The report of COSO held the belief that senior management departments' attitudes of paying attention to internal control will help to give full play to the accounting system and control procedures. Senior management departments, the key factors of internal control environment, belong to the management layer.

Control responsibilities of staff at different levels in the internal control framework system should be designed as follows:

(1) Management: The CEO is ultimately responsible for the entire control system. For large enterprises, CEO can distribute the authority to senior managers and assess their control activities. Then, senior managers regulate control procedures and member responsibilities in detail. For small enterprises, all the things are more direct and executed by the top manager. (2) Governance layer: Management is responsible for the governance layer. The latter establishes the financial function and internal audit to prevent the management' surpassing and control and deliberately distorting the fact to cover the deficiency of management. (3) Internal auditors: Internal audit is crucial to the effectiveness of assessment control system, supervising the governance structure of enterprises. (4) Other internal staffs: These people should know their own responsibilities and provide the information needed by the system and achieve corresponding control and communicate with the superior with the problems existing in the operation and illegal behaviors. (5) External members: These people contribute to the achievement of control targets. External audit can provide objective and independent evaluation and directly provide useful information for the management through financial statement audit; In addition, legal and regulatory departments, customer, other current units, financial analysts, credit rating companies, news media are helpful to the effective implementation of internal control.

So, CEO is the key to the whole control system. The due effect cannot be realized if the executors lack the related abilities or good morality, even though the internal design is well equipped. The factor of people is especially emphasized in the whole internal control environment. Honesty and morality philosophy of management layer is the guarantee for the full disclosure, prevention of deliberately hiding disadvantaged information or profited manipulation. Their lacking honesty will exert unfavored effects on the morality outlook of the whole company.

The state of senior management-enterprise environment or the culture complied by the financial report is the most significant factor for the authenticity, pointed out American Treadway ${ }^{1}$ Committee(in 1987). Although the company has a set of official rules and procedures, the cheating is likely to happen if managers are loose. In fact, the key is not the accounting members from the reason of accounting information distortion, but the managers' motivation to make surplus management and financial manipulation and fraud in the aspect of their own returns and employment. But due to the system, accounting members are usually confined to the management to supply false financial information and fraud the external information users.

Therefore, the establishment and existence of any internal control system depends on the senior management of enterprises. If they are strongly against the behavior of disobeying operation policies and internal systems, then the whole company will obtain great development; On the contrary, it will lead to the invalid internal control and accounting information disruption. One enterprise will be more successful if its senior management dedicate to establishing stable internal control environment and give staffs enough rights to develop.

The attention of management layer on the financial report is significant to avoiding the false reporting. Management layer's lacking of honesty or interest in internal control will lead to invalid internal control. Because their attitude will affect that of accounting members and other departments. For example, if the accounting schemes of enterprises punish that those managers who make false reporting or those accounting members who occasionally find but not stop financial members' will be supervised to audit and reimburse the bill to ensure the right fee confirmation. Otherwise, staffs will not carefully implement the related internal control systems if the management department don't care about the internal control and give effective support.

In fact, the management disorder in many enterprises is due to the not enough emphasis of enterprise management

${ }^{1}$ Short for National Committee of American Anti-fraud Financial Reporting 
layer on the internal control, even randomly destroying the related internal control. In the terms of Chinese cases, the key of accounting information distortion is the power structure.

\section{EFFECTS OF CONTROL ENVIRONMENT ON ACCOUNTING INFORMATION QUALITY}

\section{A. The board of directors}

Currently, there are no strict rules on one person becoming the director in our country, especially in the state owned enterprises. It seems that only catering to the will of senior government and director department is needed. In addition, the related members having the control power continue to reduce their own share in some companies after the system reform of state owned enterprises. Even if in the listed companies, the proportion of their holding shares is rather low, even to "zero". When the chairman is also the general manager, the board of directors will lose the supervision and restrict function with the general manager, which will directly affect the generated result of financial accounting information supervised by directors.

\section{B. Attitudes of management layer on accounting control}

Chinese current enterprises lack necessary methods and systems to restraint managers, and external enterprises don't have mature restraint system with managers, lacking the competition on manager market. Lots of managers in the state owned enterprises still are appointed by the government. And the traditional custom is that officials cannot be inferior that before, so the phenomenon of "The official gives the number, and the figure protects the official”. Our adopted encouraging methods are seen from many aspects for a long term, but in fact, the profit is regarded as the main balancing index so as to induce the short-term behavior of mangers.

The management layer of the enterprise regards accounting as a kind of means for its flexible operation. Accounting is supposed to provide convenience for enterprises" "enlivening" and play "brush edge ball", also coordinate and solve problems. Whoever disobeys the leaders will often be punished or even attacked. Financial members should afford the legal responsibilities if they do the things against financial system according to the demands of leaders. So, how can we judge the accounting information quality in such internal control environment?

\section{Accounting personnel quality}

A perfect personnel policy can ensure the members who executive the related policies and procedures equipped with enough abilities and integrity. Enterprises must hire enough staffs and give them ample resources to make them timely finish the assigned tasks, which is the foundation of building proper control environment. Those largely rely on the rationality level of related policies and procedures on employment, training, salaries, performance assessment and promotion. Good personnel policy can train good financial and accounting personnel. Only the integrity is not enough, and the cooperation of all departments and support of management layer are also needed. The whole personnel system will have effects it should bring when the management layer is set as the model. The management layer maybe make false reporting of accounting information for short-term performance, which will cause the distortion of accounting information.

\section{COUNTERMEASURES TO IMPROVE THE CONTROL} ENVIRONMENT TO ENHANCE ACCOUNTING INFORMATION

\section{QUALITY}

\section{A. Improve the organization structure of enterprises and increase the punish degree with providing false accounting information}

Improving the organization structure of enterprises should start form the promotion of the board of directors, which can be carried out from two aspects: first, to improve the professional knowledge level and overall quality of board members. When they have high professional standards, the behavior of the management can be better judged and identified to reduce the information asymmetry ${ }^{2}$ and effectively implement internal control. The problem can be solved by the introduction of independent directors with a certain professional level. The CSRC also clearly published the conditions for independent directors to serve, but whether they can truly be independent requires our further consideration. When we deeply realize the good influence brought by the existence of independent directors, we can form a good internal governance environment for the whole company, so as to improve the accounting information quality and the enterprise image.

Secondly, cultivate a good sense of legal system and strengthen the legal punishment. If the board of directors does not protect the interests of minority shareholders, the internal control environment will be damaged at the source, thus affecting the effective operation of the internal control mechanism of the enterprise. The board of directors is usually held by major shareholders of the enterprise, so they fail to protect medium and small shareholders' interests. In order to prevent their own profits from being affected, they will manipulate the forgery and alteration of accounting information to cause accounting information distortion. When we strengthen the punish and let them understand the cost of false accounting information far bigger than the real one, the board of directors can play its due role in internal control.

\section{B. Enhance the approval degree of enterprise management on internal control}

Seeing from the current status analysis of some enterprises, we can think that these enterprises have accounting internal control but fail to well executive it. The most important reason is that enterprise management plays the role of leading but not executive, destroys existent accounting internal

\footnotetext{
2 Information asymmetry refers to uniform and asymmetric distribution state of information among corresponding economic individuals in the market economic activity. Due to the difference of various members' understanding the related information, those people mastering rather ample information are often in a more favoring position, while those people lacking information are usually in an inferior position. That is, the difference of information possession is called information asymmetry, but it involves the contractual relationship between different actors. Otherwise, there is no so-called information asymmetry.
} 
control procedure, leading to the improper one and causing the loophole and distraction of accounting information.

The Accounting Law made it clear that the enterprise management has the related legal responsibility to implement, but such legal responsibility may be not proportional to the earnings he may get, which is the main problem of accounting information distortion. In the future, when formulating the relevant regulations on internal control, it should be clear about the responsibilities of the enterprise management, the punishment heavier than its interests. Only by this way can the whole enterprise executive internal control requirements so as to promote the healthy development of national enterprises and guarantee the accounting information quality.

\section{REFERENCES}

[1] Wang Ruiling. Establish and improve the internal control system of Chinese enterprises[J]. Friends of Accounting, 2011(02)

[2] Bai Hua and Gaoli. Internal control of financial reports: one paradox[J] Accounting research, 2011 (3)

[3] Zhu Xiaofang, Zhou Dawei and Yang Dan. Research on internal contro of state-owned enterprises based on internal control theory[J]. Accounting communication, 2012 (6)

[4] Wang Xiaoyan and Li Yuze. Study on internal control environment and accounting information distortion-taking the company of Hailian xu as an example[J]. Accounting communication, 2017 (7) 